\title{
BMJ Open How do general practitioners put preventive care recommendations into practice? A cross-sectional study in Switzerland and France
}

\author{
Paul Sebo, ${ }^{1}$ Bernard Cerutti, ${ }^{2}$ Jean-Pascal Fournier, ${ }^{3}$ Cédric Rat, ${ }^{3,4}$ \\ Fabien Rougerie, ${ }^{5}$ Nicolas Senn, ${ }^{6}$ Dagmar M Haller, ${ }^{1,6,7}$ Hubert Maisonneuve ${ }^{1}$
}

To cite: Sebo P, Cerutti B, Fournier J-P, et al. How do general practitioners put preventive care recommendations into practice? A cross-sectional study in Switzerland and France. BMJ Open 2017;7:e017958. doi:10.1136/ bmjopen-2017-017958

- Prepublication history and additional material for this paper are available online. To view please visit the journal (http:// dx.doi.org/10.1136/bmjopen2017-017958)

Received 30 May 2017 Revised 10 August 2017 Accepted 24 August 2017

CrossMark

For numbered affiliations see end of article.

Correspondence to

Dr Paul Sebo;

paulsebo@hotmail.com

\section{ABSTRACT}

Objectives We previously identified that general practitioners (GPs) in French-speaking regions of Europe had a variable uptake of common preventive recommendations. In this study, we describe GPs' reports of how they put different preventive recommendations into practice.

Design, setting and participants Cross-sectional study conducted in 2015 in Switzerland and France. 3400 randomly selected GPs were asked to complete a postal $(n=1100)$ or online $(n=2300)$ questionnaire. GPs who exclusively practiced complementary and alternative medicine were not eligible for the study. 764 GPs (response rate: postal 47\%, online 11\%) returned the questionnaire (428 in Switzerland and 336 in France).

Main outcome measures We investigated how the GPs performed five preventive practices (screening for dyslipidaemia, colorectal and prostate cancer, identification of hazardous alcohol consumption and brief intervention), examining which age group they selected, the screening frequency, the test they used, whether they favoured shared decision for prostate cancer screening and their definition of hazardous alcohol use.

Results A large variability was observed in the way in which GPs provide these practices. $41 \%$ reported screening yearly for cholesterol, starting and stopping at variable ages. $82 \%$ did not use any test to identify hazardous drinking. The most common responses for defining hazardous drinking were, for men, $\geq 21$ drinks/ week ( $24 \%$ ) and $\geq 4$ drinks/occasion for binge drinking (20\%), and for women, $\geq 14$ drinks/week (28\%) and $\geq 3$ drinks/occasion (21\%). Screening for colorectal cancer, mainly with colonoscopy in Switzerland (86\%) and stoolbased tests in France (93\%), was provided every 10 years in Switzerland (65\%) and 2 years in France $(91 \%)$ to patients between 50 years (87\%) and 75 years $(67 \%)$. Prostate cancer screening, usually with shared decision $(82 \%)$, was provided yearly $(62 \%)$ to patients between 50 years $(74 \%)$ and $75-80$ years $(32 \%-34 \%)$.

Conclusions The large diversity in the way these practices are provided needs to be addressed, as it could be related to some misunderstandingof the current guidelines, to barriers for guideline uptake or, more likely, to the absence of agreement between the various recommendations.

\section{Strengths and limitations of this study}

- We previously identified that general practitioners (GPs) in French-speaking regions in Europe had a variable uptake of common preventive recommendations but, to our knowledge, no studies assessed how GPs perform preventive activities in these countries.

- All the answers were self-reported, which could lead to social desirability biases.

- The recruitment of GPs was restricted to four Frenchspeaking regions (two in Western Switzerland and two in France); this relatively restricted sample may not be representative of all GPs practicing either in Europe or in French-speaking continental Europe.

\section{INTRODUCTION}

Preventive healthcare practices can be effective strategies to reduce the burden of chronic diseases such as cancer or heart diseases. ${ }^{1-4}$ Because chronic diseases are a major cause of morbidity and mortality worldwide, preventive healthcare practices have the potential to lower medical costs. ${ }^{3}$ A large number of chronic diseases is associated with identified and modifiable risk factors. ${ }^{5}{ }^{6}$ Therefore, despite remaining controversies regarding the relevance of some preventive recommendations, ${ }^{7-9}$ prevention has become an essential component of general practitioners' (GPs) tasks.

There has been increasing emphasis on the development of evidence-based preventive care guidelines in the last decades, such as the US Preventive Services Task Force recommendations and the Canadian Task Force on Preventive Health Care. ${ }^{10} 11$ These North American guidelines are often used by GPs in Europe, in combination with country-specific recommendations. For example, a national programme named EviPrev was recently launched in 
Switzerland to develop local guidelines, taking into account the Swiss context. ${ }^{12}$ These recommendations have only recently started to be implemented in clinical practice, and a majority of Swiss GPs do not know them in detail. In France, preventive guidelines were mostly developed and classified by diseases. There are currently no global preventive care recommendations in this country. ${ }^{5}$ Some preventive care recommendations are available, but they are scattered across various disease-specific guidelines published by a variety of academic associations. ${ }^{5}$

Unfortunately, many of these guidelines offer contradictory advice. As there is no consensus, it is difficult for GPs to determine how to deliver preventive care in their consultations. ${ }^{5}$ The methodology and choice of grading systems to develop these guidelines vary, as well as the choice of the clinical categories and the target populations, which further complicates the delivery of preventive care. ${ }^{5}$ In such a context, it may be difficult for GPs to have a precise, global picture of the preventive care they are expected to deliver.

Some studies addressed the variation in and the barriers to guideline adherence. ${ }^{13-17}$ Among a wide spectrum of barriers, the lack of awareness or familiarity with the guidelines is often cited by GPs. ${ }^{16} 17$ This factor may, at least in part, be explained by the lack of agreement between the recommendations and, in many countries, by the absence of national programme dedicated to implementation of prevention guidelines in general practices. Moreover, GPs seem to perceive some recommendations as not being applicable in daily practice, either because their patient populations are highly heterogeneous or because they are 'complex'. ${ }^{16}{ }^{17}$ These barriers could probably in part be overcome if GPs were more often involved in the development process of these guidelines, which is often not the case. ${ }^{16}$

The lack of awareness of the local guidelines and the discrepancies between the various available guidelines could alter the way the different recommendations are carried out. Therefore, in order to add new data coming from French-speaking Continental Europe to the literature assessing how GPs perform preventive activities, we found that it is important to explore how they are provided regarding both the target populations and the screening tests used by documenting self-reported preventive care practices in four Frenchspeaking regions. We also aimed to investigate whether these findings were associated with some GP characteristics, in particular their country of practice (Switzerland and France). The two countries differ in several aspects related to medical practice, as for example methods of reimbursement of medical costs (benefits are based on preset rates in France and fee-for-service in Switzerland) and in preventive recommendations (no unified preventive recommendations' document in France). ${ }^{5}$

\section{METHODS}

\section{Study site, study population and sample size justification}

This study was part of a larger project designed to assess French-speaking GPs' preventive care practices. This was a cross-sectional autoadministered questionnaire-based study that took place in 2015 in four French-speaking regions in two countries (Switzerland: cantons of Geneva and Vaud; and France: Alsace and Pays de la Loire). Alsace and Pays de Loire are approximately in the mid-French level in relation to rurality, medical density and GPs' density. ${ }^{18}{ }^{19}$ Vaud and Geneva are more urban than other cantons in Switzerland and their total medical density and GPs' density exceed average Swiss values. ${ }^{20-22}$

We randomly selected 1000 community-based GPs practicing in Switzerland (600 in the canton of Geneva and 400 in the canton of Vaud) and 2400 in France (1200 in Alsace and 1200 in Pays de la Loire) from the regional professional organisation lists and invited them to participate in the study by email (300 in Switzerland and 2000 in France) or by post (700 in Switzerland and 400 in France). We sent reminder messages (maximum twice per GP) if they had not responded to the first invitation. We used simple randomisation based on computer-generated random numbers to allocate them to the postal or the web-based group. The postal letters included a stamped return envelope. GPs who exclusively practiced complementary and alternative medicine were not eligible to take part in our project. No other exclusion criteria were applied to the study. We described the recruitment process in detail in a previous paper. ${ }^{23}$

\section{Sample size estimation}

We estimated the minimal required sample size of 600 to be able to provide a $95 \%$ CI no wider than $\pm 4 \%$ for every estimate of prevalence of preventive activities, with an expected prevalence of about $50 \%{ }^{24}{ }^{25}$ As we assumed a participation rate of $25 \%$, we had to contact $2400 \mathrm{GPs}$. We decided to increase the sample size to 3400 to take into account the presence of incomplete questionnaires. ${ }^{2627}$

\section{Data collection}

A research assistant located in Geneva contacted the randomly selected GPs practicing in Switzerland (in France, this task was carried out by the local GPs' representative structure: Union Régionale des Professionnels de Santé Alsace and Pays de la Loire) and informed them about the aim of the study and the practical procedures to be followed to complete the anonymous questionnaire.

The questionnaire (see online supplementary file 1) included sociodemographic questions (age, gender, number of working days per week and number of working years in the practice), and questions about the frequency of use of 12 preventive practices (blood pressure, weight and height measurements, screening for dyslipidaemia, hazardous drinking (and advice to decrease drinking for hazardous drinkers), tobacco smoking (and advice to stop smoking for smokers), colorectal and prostate cancer; and influenza immunisation for patients $>65$ years and 
at-risk patients $<65$ years), using a 5-point Likert scale ranging from 'never performed' to 'always performed'.

Ten of these preventive practices were selected because they had been part of previous studies evaluating the quality of preventive care in Switzerland ${ }^{28}$ We added two additional practices: cholesterol measurement, because it is a highly recommended intervention in preventive care, and screening for prostate cancer, because several Swiss and French medical agencies recently recommended against systematic screening. ${ }^{59-31}$ We did not include diabetes screening in our project, because it is only recommended when other cardiovascular risk factors are present. ${ }^{32}{ }^{33}$ We did not include screening for breast and cervical cancer either because, in Switzerland, they are often carried out by gynaecologists, in particular in mostly urban cantons such as Geneva and Vaud.

We restricted the data presented here to five preventive care practices for which we asked additional questions about how GPs were providing them (four practices regarding screening: dyslipidaemia, hazardous drinking, colorectal and prostate cancer; and one regarding counselling: advice to decrease drinking for hazardous drinkers). These five practices were selected because they illustrate the three major topics leading to high morbidity and mortality in most high-income countries (cardiovascular diseases, cancers and addictions) and because they can be applied in a variety of ways. ${ }^{34}{ }^{35}$ For the screening of dyslipidaemia, colorectal and prostate cancers, we asked GPs to specify screening starting and ending ages and screening frequency. We also asked which diagnostic test they were generally using for the screening of dyslipidaemia (full lipid profile or total cholesterol) and colorectal cancer (colonoscopy or stool-based tests (guaiac faecal occult blood test or faecal immunochemical test (FIT)) and whether they usually screened for prostate cancer in the context of a shared and informed decision process. Finally, we asked them whether they used a validated questionnaire to screen for hazardous drinking (and if yes, which one) and which definitions of hazardous, including binge drinkers, they were generally using.

Seven GPs pretested the questionnaire so as to ensure that it was understandable and easy to complete. All collected data remained confidential throughout the study. We assumed that a tacit consent was given when a GP returned the completed questionnaire. We did not collect any data regarding GPs who had refused to participate in the study. In Switzerland, informed consent waiving was granted by the Research Ethics Committee of Geneva (under Swiss law informed consent is required when collecting personal health data, not when exploring practices), whereas in France, the research protocol was approved by the Groupe nantais d'éthique en santé (ref: 2015-09-06).

\section{Statistical analyses}

We computed the proportion of GPs delivering each of the five preventive practices, defined as the proportion of
GPs scoring 4 or $5 / 5$ on the Likert scale, with estimated 95\% CIs. Proportions were also split by country, gender and age group. Multivariate analysis adjusting for country, gender and class of age were also performed. Differences of proportion were tested with $\chi^{2}$ tests. For quantitative values (eg, age, frequency and number of glasses) t-test were used. Statistical significance was set at a two-sided $\mathrm{p}$ value of $\leq 0.05$. All the analyses were carried out with TIBCO Spotfire S+ 8.1 for Windows (TIBCO Software, Palo Alto, California, USA) or R V.3.2.2 (R Foundation for Statistical Computing, Vienna, Austria).

\section{RESULTS}

Among the 3400 GPs who were selected at random (1000 in Switzerland and 2400 in France), 764 (response rate: $47 \%$ in postal group and $11 \%$ in online group) responded to the questionnaire (428 in Switzerland and 336 in France). Table 1 presents their main sociodemographic characteristics, overall and by country of practice. The GPs' distribution by gender was relatively similar in the two countries (men: $59 \%$ in Switzerland vs 58\% in France), as well as the number of half-days worked per week ( 8.5 vs 8.7 ). Some differences could be observed regarding the age distribution (>64 years: $13 \%$ in Switzerland vs $6 \%$ in France; $<35$ years: $1 \%$ in Switzerland vs $8 \%$ in France) and the number of working years in the current practice (20 in France vs 17 in Switzerland). Our sample appears to be similar in age and gender to all GPs practicing in Switzerland (professional organisation of Swiss physicians, 2016: median age 54 years (vs 54 years in our study), men 59\% (vs 59\% in our study)) and France (Pays de Loire, 2013: median age 51 years (vs 48 years in our study), men $57 \%$ (vs $53 \%$ in our study)). ${ }^{22} 36$

Tables 2 and 3 show the self-reported preventive care practices in the two countries. A large variability was observed in the way in which GPs applied these preventive recommendations. In general, screening for dyslipidaemia (93\% with full lipid profile test) was provided yearly to patients who were $40-80$ years old. The vast majority of GPs did not use any test to screen for hazardous drinking (77\% in Switzerland and $91 \%$ in France), but when they did use one, the CAGE was most frequently chosen in both countries. For the majority of GPs, hazardous drinking was defined as the consumption of $\geq 21$ drinks/week for men and 14 drinks/week for women, and as $\geq 4$ drinks/ occasion for men and three drinks/occasion for women, for both countries. Screening for colorectal cancer, mainly with colonoscopy in Switzerland (86\%) and FIT in France $(93 \%)$, was provided every 10 years in Switzerland and every 2 years in France to patients who were 50-75 years old. Finally, screening for prostate cancer, usually in the context of a shared decision (82\%), was provided yearly to patients who were 50 to $75-80$ years old.

Online supplementary file 2 and supplementary file 3 show the self-reported GPs' preventive care practices by GP gender and age group (for online supplementary file 2 screening for dyslipidaemia and hazardous 
Table 1 General practitioners' characteristics in the two countries $(n=764)$

\begin{tabular}{|c|c|c|c|c|}
\hline Characteristics & Switzerland $(n=428)$ & France $(n=336)$ & & Total $(n=764)$ \\
\hline & $\mathrm{n}^{*}(\%)$ & $\mathrm{n}^{*}(\%)$ & $\mathrm{p}$ Valuet & $\mathrm{n}^{*}(\%)$ \\
\hline \multicolumn{5}{|l|}{ Gender } \\
\hline Male & $240(59.1)$ & $188(58.0)$ & 0.83 & $428(55.6)$ \\
\hline Female & $166(40.9)$ & $136(42.0)$ & & $302(44.4)$ \\
\hline \multicolumn{5}{|l|}{ Age group (years) } \\
\hline$<35$ & $2(0.5)$ & $27(8.2)$ & $<0.001$ & $29(3.9)$ \\
\hline $35-44$ & $94(23.1)$ & $63(19.0)$ & & $157(21.3)$ \\
\hline $45-54$ & $112(27.5)$ & $86(26.0)$ & & $198(26.8)$ \\
\hline $55-64$ & $148(36.4)$ & $134(40.5)$ & & $282(38.2)$ \\
\hline \multirow[t]{2}{*}{$>64$} & $51(12.5)$ & $21(6.3)$ & & $72(9.8)$ \\
\hline & Mean \pm SD & Mean \pm SD & & Mean \pm SD \\
\hline Mean number of half-days worked per week & $8.5 \pm 2.5$ & $8.7 \pm 2.0$ & 0.31 & $8.6 \pm 2.3$ \\
\hline Number of working years in the current practice & $16.7 \pm 10.5$ & $19.6 \pm 11.5$ & $<0.001$ & $18.0 \pm 11.1$ \\
\hline
\end{tabular}

*Numbers do not add up to 428,336 and 764 because of missing values.

†Comparisons of proportions were made with $\chi^{2}$ tests; comparisons of continuous values were made with Student's t-test.

drinking and online supplementary file 3 for colorectal and prostate cancer screening). There are only very few differences between the groups regarding the characteristics of the preventive care practices. Colorectal cancer screening was proposed (with colonoscopy) every 10 years by a majority of GPs $<55$ years $(70 \%)$, and prostate cancer yearly by a majority of female GPs $(69 \%)$, whereas higher dispersions (ie, higher variability) were observed among older GPs for colorectal cancer and male GPs for prostate cancer.

\section{DISCUSSION}

\section{Summary}

We identified a large variability in the way in which French-speaking GPs apply preventive care recommendations. The association between GPs' gender, age and country of practice and the way they apply preventive recommendation is generally small, except for screening for colorectal cancer (colonoscopy in Switzerland vs FIT in France).

\section{Comparison with existing literature}

The results of this study showed a high diversity in the way preventive care was provided by GPs, which frequently was not in accordance with local guidelines (see online supplementary file 4 for Swiss ${ }^{12} 293233$ 37-39 and French recommendations ${ }^{6} 303140-45$ on how GPs are expected to deliver these five preventive care practices). Screening for colorectal cancer is however the archetypal example of a screening carried out according to the usual recommendations. Indeed, a large majority of GPs screen the recommended target population (patients between 50 and 75 years old), using common screening tests (colonoscopy or stool-based tests in Switzerland and mainly stool-based tests in France), with the recommended screening frequency (every 10 years for colonoscopy in Switzerland and every 2 years for FIT in France). Note that stool-based tests are provided by less than one-fifth of Swiss GPs, though it is an alternative recommended screening test for colorectal cancer in this country. This finding is in accordance with a recent study showing a growth in colorectal cancer screening due to greater use of endoscopy (increase of colonoscopy utilisation from $8 \%$ to $15 \%$ and decrease of stool-based tests utilisation from $13 \%$ to $10 \%$ between 2007 and 2012).${ }^{46}$ FIT (and not colonoscopy) is the most frequently used test in France as part of the national screening programme for colorectal cancer in this country. However, it should be borne in mind that FIT is the recommended screening test for general populations without specific risk factors. Colonoscopy, however, is recommended for higher risk patients such as, for example, patients with a family history of colorectal cancer. There is currently no national screening programme in Switzerland.

Different results with much higher heterogeneity are observed for screening for dyslipidaemia and prostate cancer and counselling for hazardous alcohol consumption. Only one-third of Swiss and French GPs screen for dyslipidaemia as from the age of 40 years (the recommended starting age in the two countries), and only $8 \%$ of Swiss GPs and 20\% of French GPs, respectively, follow the recommended 5-year screening frequency.

Similarly, though the majority of GPs screen prostate cancer from 50 years (the recommended starting age for Switzerland), less than one-third of Swiss GPs stops screening at the recommended age of 75 years (almost half of Swiss GPs stops screening at 70 or 80 years).

For the majority of GPs, hazardous drinking was defined as the consumption of $\geq 21$ drinks/week for men and 14 drinks/week for women, and as $\geq 4$ drinks/occasion 
Table 2 Self-reported preventive care practices of general practitioners in the two countries: screening for dyslipidaemia and hazardous drinking

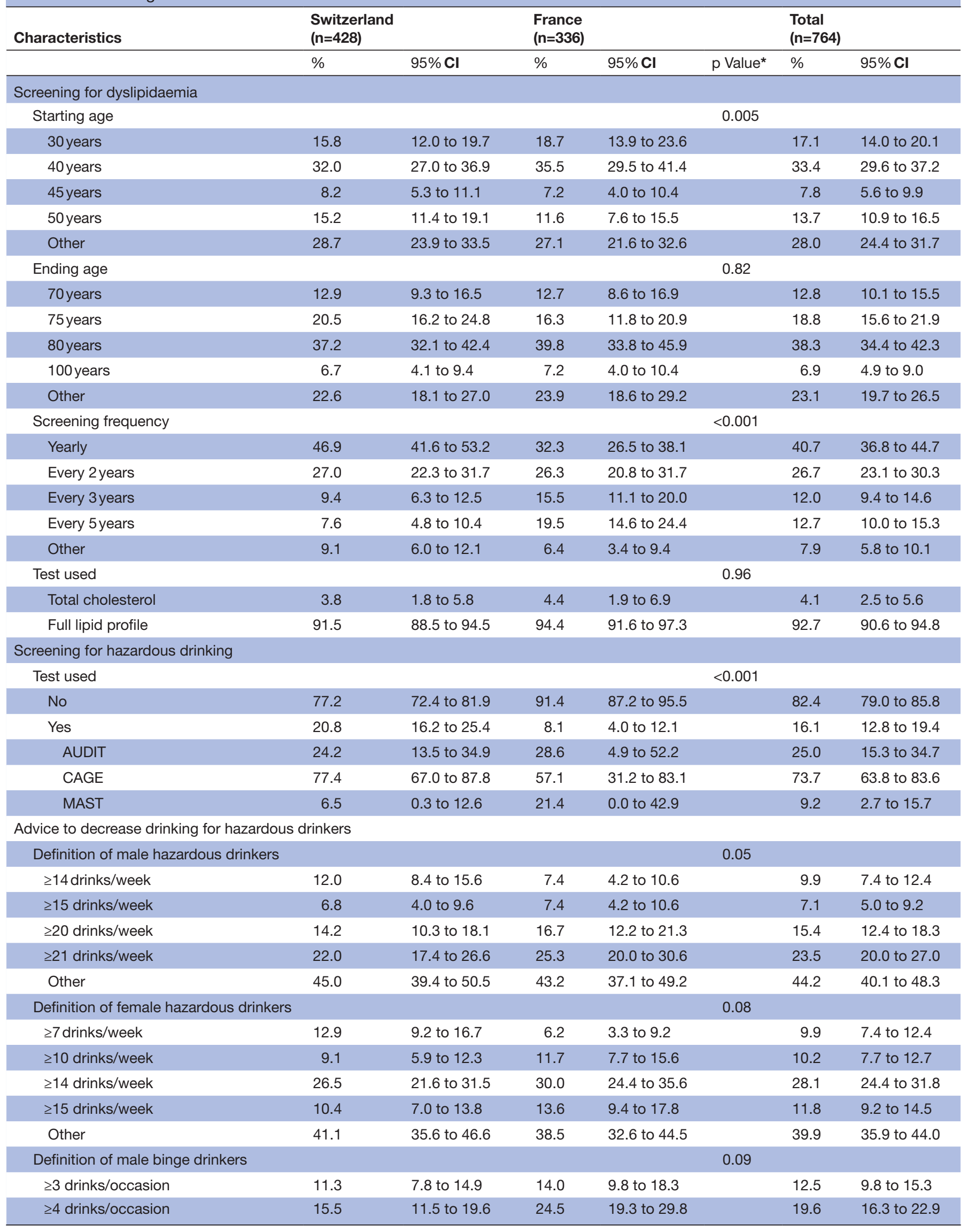




\begin{tabular}{|c|c|c|c|c|c|c|c|}
\hline \multirow[t]{2}{*}{ Characteristics } & \multicolumn{2}{|c|}{$\begin{array}{l}\text { Switzerland } \\
(n=428)\end{array}$} & \multicolumn{2}{|c|}{$\begin{array}{l}\text { France } \\
(n=336)\end{array}$} & \multirow[b]{2}{*}{ p Value* } & \multicolumn{2}{|c|}{$\begin{array}{l}\text { Total } \\
(n=764)\end{array}$} \\
\hline & $\%$ & $95 \% \mathbf{C l}$ & $\%$ & $95 \% \mathbf{C l}$ & & $\%$ & $95 \% \mathbf{C l}$ \\
\hline$\geq 5$ drinks/occasion & 13.9 & 10.1 to 17.8 & 15.6 & 11.1 to 20.0 & & 14.7 & 11.7 to 17.6 \\
\hline$\geq 6$ drinks/occasion & 6.2 & 3.5 to 8.8 & 8.2 & 4.8 to 11.5 & & 7.1 & 5.0 to 9.2 \\
\hline Other & 53.1 & 47.5 to 58.6 & 37.7 & 31.8 to 43.7 & & 46.1 & 42.0 to 50.2 \\
\hline Definition of female binge drinkers & & & & & 0.22 & & \\
\hline$\geq 2$ drinks/occasion & 10.4 & 7.0 to 13.8 & 15.6 & 11.1 to 20.0 & & 12.7 & 10.0 to 15.5 \\
\hline$\geq 3$ drinks/occasion & 19.4 & 15.0 to 23.8 & 23.3 & 18.2 to 28.5 & & 21.2 & 17.8 to 24.6 \\
\hline$\geq 4$ drinks/occasion & 13.9 & 10.1 to 17.8 & 15.6 & 11.1 to 20.0 & & 14.7 & 11.7 to 17.6 \\
\hline$\geq 5$ drinks/occasion & 7.1 & 4.3 to 10.0 & 10.5 & 6.8 to 14.3 & & 8.7 & 6.3 to 11.0 \\
\hline Other & 49.2 & 43.6 to 54.8 & 35.0 & 29.2 to 40.9 & & 42.8 & 38.7 to 46.8 \\
\hline
\end{tabular}

${ }^{*}$ Comparisons of proportions were made with $\chi^{2}$ tests.

AUDIT, Alcohol Use Disorders Identification Test; CAGE, acronym of its four questions (Cut down, Annoyed, Guilty, Eye-opener); MAST, Michigan Alcoholism Screening Test.

for men and three drinks/occasion for women, for both countries. Note that, in recent years, several countries have revised their guidelines regarding hazardous alcohol drinking, including France. ${ }^{47}$ The French expert group recommends in its recent publication (May 2017) that alcohol consumers take no more than 10 standard drinks per week and no more than two standard drinks per day for men and women. ${ }^{47}$ These thresholds have been chosen, because they represent an absolute lifetime risk of alcohol-related mortality for the French population between $1 \%$ and 1 per 1000 .

Some of the reasons for not performing prevention practices according to recommendations (such as lack of time and method of reimbursement for medical care) can vary between countries, which could partly explain the country differences in our study. In France, the healthcare system is separated into three sectors and GPs have to choose in which sector they wish to work. The government regulates rates for medical consultations within sector 1 (ie, preset fixed fees per consultation). In Sector 2, higher fees are allowed within reason, and in sector 3, there are no fee limits. A large majority of GPs are in sector 1. By contrast, the Swiss ambulatory healthcare system is based on fee-for-service payments that are related to the consultation time. ${ }^{48}$

Major changes in GPs' profile and activities are observed in many Western countries (including France and Switzerland). Nowadays, GPs are older, more often female and they more often work in group practices. ${ }^{48}$ In Switzerland, whereas the number of face-to-face consultations is lower, the median time of consultation tends to be longer (20 min vs 15 min in France). ${ }^{48-50}$ When compared with other European countries, the consultation time is particularly high in Switzerland. ${ }^{49}$

The large diversity in the way screening for dyslipidaemia and prostate cancer are provided could be related to three interrelated factors: lack of knowledge of the current guidelines, barriers to guideline adherence and lack of agreement between the various available recommendations. ${ }^{51617}$

The relative lack of knowledge of the guidelines could in part be attributed to the rapid evolution of scientific knowledge, which in turn requires frequent modifications in the guidelines. However, this factor (lack of awareness) is probably also explained by lack of agreement between the various recommendations, which is corroborated by our finding that a large majority of GPs screen for colorectal cancer appropriately, that is, in accordance with the recommendations; indeed, the guidelines used for screening colorectal cancer show a relatively high level of agreement compared with those proposed in relation to screening for dyslipidaemia and prostate cancer.

The variability of the current guidelines is probably not linked to variations in access to scientific knowledge, because all medical agencies, researchers and experts are expected to develop their recommendations on the same evidencebased data. ${ }^{5}$ Differences in settings, local epidemiological, socioeconomic and cultural contexts, perceptions of healthcare priorities and health delivery systems, may all explain some of the discrepancies between the guidelines. ${ }^{5}$

Among a wide spectrum of barriers to guideline adherence, such as lack of motivation, patients' preferences, time and organisational constraints, GPs may perceive some recommendations as not being applicable in daily practice. ${ }^{16} 17$ These barriers could probably be in part overcome if GPs were more often involved in the development of these guidelines. More frequent appraisal and adaptation of guidelines using an assessment instrument such as Appraisal of Guidelines for Research and Evaluation is also an essential way of favouring higher uptake by GPs. ${ }^{51}$ Yet, the lack of awareness or familiarity with the guidelines is often mentioned by GPs as a barrier to guideline adherence, which again may be related to the diversity of current guidelines and to the absence of national programmes to implement prevention guidelines in general practices in French-speaking countries. ${ }^{16} 17$ 
Table 3 Self-reported preventive care practices of general practitioners in the two countries: screening for colorectal and prostate cancer

\begin{tabular}{|c|c|c|c|c|c|c|c|}
\hline Characteristics & $\begin{array}{l}\text { Switzerland } \\
(\mathrm{n}=428)\end{array}$ & & $\begin{array}{l}\text { France } \\
(n=336)\end{array}$ & & & $\begin{array}{l}\text { Total } \\
(n=764)\end{array}$ & \\
\hline & $\%$ & $95 \% \mathrm{Cl}$ & $\%$ & $95 \% \mathrm{Cl}$ & p Value* & $\%$ & $95 \% \mathbf{C l}$ \\
\hline Starting age & & & & & $<0.001$ & & \\
\hline 40 years & 3.4 & 1.5 to 5.3 & 7.3 & 4.3 to 10.3 & & 5.2 & 3.4 to 6.9 \\
\hline Other & 5.7 & 3.3 to 8.1 & 5.5 & 2.9 to 8.2 & & 5.6 & 3.8 to 7.4 \\
\hline Ending age & & & & & $<0.001$ & & \\
\hline 70 years & 17.1 & 13.2 to 21.1 & 9.0 & 5.7 to 12.3 & & 13.5 & 10.8 to 16.1 \\
\hline 74 years & 0.3 & 0.0 to 0.8 & 9.7 & 6.3 to 13.1 & & 4.5 & 2.9 to 6.2 \\
\hline Test used & & & & & $<0.001$ & & \\
\hline Colonoscopy & 86.3 & 82.7 to 89.9 & 5.2 & 2.6 to 7.7 & & 49.6 & 45.7 to 53.5 \\
\hline FOBT or FIT & 12.0 & 8.6 to 15.4 & 93.1 & 90.2 to 96.0 & & 48.7 & 44.8 to 52.5 \\
\hline Screening frequency if colonoscopy & & & & & $<0.001$ & & \\
\hline 5 years & 18.5 & 14.2 to 22.9 & 66.7 & 42.8 to 90.5 & & 20.8 & 16.4 to 25.3 \\
\hline 10 years & 64.9 & 59.5 to 70.3 & 0.0 & & & 61.8 & 56.5 to 67.2 \\
\hline Other & 16.6 & 12.4 to 20.7 & 33.3 & 9.5 to 57.2 & & 17.5 & 13.2 to 21.5 \\
\hline Screening frequency if FOBT or FIT & & & & & 0.70 & & \\
\hline Yearly & 31.0 & 17.0 to 44.9 & 2.2 & 0.5 to 4.0 & & 6.1 & 3.4 to 8.8 \\
\hline Other & 19.4 & 14.4 to 24.4 & 14.1 & 9.1 to 19.0 & & 17.0 & 13.5 to 20.6 \\
\hline Ending age & & & & & 0.25 & & \\
\hline 70 years & 19.4 & 14.4 to 24.4 & 7.3 & 3.6 to 11.0 & & 14.0 & 10.7 to 17.3 \\
\hline 75 years & 31.2 & 25.3 to 37.1 & 37.0 & 30.2 to 43.8 & & 33.8 & 29.3 to 38.3 \\
\hline 80 years & 28.3 & 22.5 to 34.0 & 36.5 & 29.7 to 43.3 & & 31.9 & 27.5 to 36.3 \\
\hline Other & 21.1 & 15.9 to 26.3 & 19.3 & 13.7 to 24.8 & & 20.3 & 16.5 to 24.1 \\
\hline Screening frequency & & & & & $<0.001$ & & \\
\hline Yearly & 52.3 & 46.0 to 58.7 & 72.9 & 66.6 to 79.2 & & 61.5 & 56.9 to 66.1 \\
\hline 2 years & 32.1 & 26.1 to 38.0 & 21.9 & 16.0 to 27.7 & & 27.5 & 23.3 to 31.7 \\
\hline Other & 15.6 & 11.0 to 20.2 & 5.2 & 2.1 to 8.4 & & 11.0 & 8.0 to 13.9 \\
\hline Shared decision & 88.2 & 81.2 to 92.3 & 75.0 & 68.9 to 81.1 & $<0.001$ & 82.3 & 78.7 to 85.9 \\
\hline
\end{tabular}

${ }^{*}$ Comparisons of proportions were made with $\chi^{2}$ tests.

FIT, faecal immunochemical test; FOBT, faecal occult blood test.

Over the last decades, attention mainly focused on underuse of various preventive practices, such as screening for dyslipidaemia and cancers. ${ }^{52}$ However, overuse can also be problematic because of unnecessary costs as well as patient burden (psychological and other risks) from overdiagnosis. We showed that a certain number of GPs overuse preventive practices (eg, overall, $17 \%$ of GPs report starting screening for dyslipidaemia at 30 years, whereas 40 years is the recommended starting age in the two countries). Overutilisation of preventive practices has 
been shown in particular for dyslipidaemia as well as for colorectal, breast, cervical and prostate cancer ${ }^{52} 53$ and could be explained in two ways: lack of knowledge of the current guidelines and also by the fact that GPs could be put under pressure by their patients to perform certain practices, even if they are not recommended. Overuse of lab tests-based screening (such as screening for dyslipidaemia) has also been shown in patients requiring repeat blood tests to follow-up various comorbidities and in relation to treat-to-target lipid lowering strategies. ${ }^{54}$

Several actions may help to improve the current situation and overcome the obstacles that have been identified above (gaps in knowledge, barriers to guideline adherence and lack of agreement between guidelines). For example, we could mention the development and implementation of guidelines specifically dedicated to prevention activities, the involvement of GPs in their development and in the establishment of a prioritisation process, the organisation of nationwide campaigns, the use of recall systems and the implementation of a systematic performance monitoring. ${ }^{565}$ However, we consider that these practices should be complemented by harmonisation of the current guidelines, at least at a European level, to be fully effective. There is often a low level of agreement between the various guidelines and high variability in the choice of methodology and grading system is observed in their development. The choice of the clinical categories and the target populations could also be problematic, resulting in a number of difficulties to determine to whom and how preventive care should be provided.

\section{Limitations}

Several limitations should be kept in mind when considering the results of this study. First, all the answers were self-reported, which could lead to social desirability biases (ie, natural tendency to engage in socially desirable responding by over-reporting good behaviour and/or under-reporting undesirable behaviour) ${ }^{56}$ Second, the recruitment of GPs was restricted to four French-speaking regions (two in Western Switzerland and two in France); this relatively restricted sample may not be representative of all GPs practicing either in Europe or in Frenchspeaking continental Europe. Third, although nearly half of those invited to participate by post returned the questionnaire, response rates in those who were invited to respond online were very low $(11 \%)$. Therefore, the hypothesis of a different profile between responders and non-responders cannot be ruled out. However, we assumed a total participation rate of $25 \%$ in the calculation of our sample size, and our study sample size was in fact higher than the estimated minimal required sample size for our study. In addition, our sample appears to be representative in terms of age and gender of all GPs practicing in Switzerland and France (data from Pays de la Loire). The fact that response rates were higher for Swiss (43\%) compared with French GPs (14\%) could also introduce a certain degree of selection bias. Fourth, though the GPs practicing in Switzerland showed fairly similar sociodemographic characteristics to those practicing in France, they were some slight differences regarding the age distribution and the experience as GP, which might have led to additional bias.

\section{Implications for research and practice}

In conclusion, the large heterogeneity in the way preventive care is provided need to be addressed, as it could be related to some misunderstanding of the current guidelines, to barriers to guideline adherence or, more likely, to the absence of agreement between the various recommendations. Considerable efforts should be made to harmonise the current guidelines and implement them in primary care offices. This is an essential task to improving the quality of preventive care and, in fine, to reducing the burden of chronic diseases and medical costs.

\section{Author affiliations}

${ }^{1}$ Primary Care Unit, University of Geneva, Faculty of Medicine, Geneva, Switzerland ${ }^{2}$ Unit of Research and Development in Medical Education, University of Geneva, Faculty of Medicine, Geneva, Switzerland

${ }^{3}$ Department of General Practice, University of Nantes, Faculty of Medicine, Nantes, France

${ }^{4}$ Unit 1232 - team 2, French National Institute of Health and Medical Research (INSERM), Nantes, France

${ }^{5}$ Department of General Medicine, University of Strasbourg, Faculty of Medicine, Strasbourg, France

${ }^{6}$ Department of Ambulatory Care and Community Medicine, University of Lausanne, Lausanne, Switzerland

${ }^{7}$ Department of Community, Primary Care and Emergency Medicine \& Paediatrics, Geneva University Hospitals, Geneva, Switzerland

Acknowledgements We would like to warmly thank all the doctors who participated in this study, Antoine Abhamon, our research assistant and the Unions Régionales des Professionnels de Santé (URPS) Alsace and Pays de la Loire, who were responsible for the organisational aspects of the project, and Drs JeanBaptiste Caillard and Thomas Herault for their support and assistance throughout the study.

Contributors PS, DMH and HM were involved in the conception of the study and data interpretation. PS drafted the first version of the manuscript. BC was involved in the data analysis and data interpretation. J-PF, CR, FR and NS were involved in the data interpretation and critically revising the manuscript. All authors read and approved the final manuscript.

Funding This project was supported by institutional funding from the Faculty of Medicine, University of Geneva, and by a funding from the Union Régionale des Professionnels de santé (URPS) Alsace and Pays de la Loire and from the Collège regional desgénéralistes enseignants d'Alsace.

\section{Competing interests None declared.}

Ethics approval In Switzerland, informed consent waiving was granted by the Research Ethics Committee of Geneva (under Swiss law informed consent is required when collecting personal health data, not when exploring practices), whereas, in France, the research protocol was approved by the Groupe nantais d'éthique en santé (ref: 2015-09-06).

Provenance and peer review Not commissioned; externally peer reviewed.

Data sharing statement No additional unpublished data from the study. BC can be contacted for access to the dataset underlying the current analysis.

Open Access This is an Open Access article distributed in accordance with the Creative Commons Attribution Non Commercial (CC BY-NC 4.0) license, which permits others to distribute, remix, adapt, build upon this work non-commercially, and license their derivative works on different terms, provided the original work is properly cited and the use is non-commercial. See: http://creativecommons.org/ licenses/by-nc/4.0/ 
(c) Article author(s) (or their employer(s) unless otherwise stated in the text of the article) 2017. All rights reserved. No commercial use is permitted unless otherwise expressly granted.

\section{REFERENCES}

1. Ezzati M, Hoorn SV, Rodgers A, et al. Estimates of global and regional potential health gains from reducing multiple major risk factors. Lancet 2003;362:271-80.

2. Shield KD, Parkin DM, Whiteman DC, et al. Population attributable and preventable fractions: cancer risk factor surveillance and cancer policy projection. Curr Epidemiol Rep 2016;3:201-11.

3. Xu F, Town M, Balluz LS, et al. Surveillance for certain health behaviors among States and selected local areas - United States, 2010. MMWR Surveill Summ 2013;62:1-247.

4. Nelson DE, Bland S, Powell-Griner E, et al. State trends in health risk factors and receipt of clinical preventive services among US adults during the 1990s. JAMA 2002;287:2659-67.

5. Gelly J, Mentre F, Nougairede M, et al. Preventive services recommendations for adults in primary care settings: agreement between Canada, France and the USA--a systematic review. Prev Med 2013;57:3-11.

6. Gelly J. Optimisation des stratégies préventives en médecine générale. Paris 7, 2014. http://www.theses.fr/2014PA077209

7. Krogsbøll LT, Jørgensen KJ, Grønhøj Larsen C, et al. General health checks in adults for reducing morbidity and mortality from disease: cochrane systematic review and meta-analysis. BMJ 2012;345:e7191.

8. Saquib N, Saquib J, loannidis JP. Does screening for disease save lives in asymptomatic adults? Systematic review of meta-analyses and randomized trials. Int J Epidemiol 2015;44:264-77.

9. Dyakova M, Shantikumar S, Colquitt JL, et al. Systematic versus opportunistic risk assessment for the primary prevention of cardiovascular disease. Cochrane Database Syst Rev 2016:CD010411.

10. US Preventive Services Task Force - recommendations for Primary Care Practice. http://www. uspreventiveservicestaskforce.org/Page/ Name/recommendations

11. Canadian task force on preventive health care. Clinical practice guidelines. http://canadiantaskforce.ca/ctfphc-guidelines/overview/

12. Cornuz J, Auer R, Neuner-Jehle S, et al. [Swiss recommendations for the check-up in the doctor's office]. Rev Med Suisse 2015:11:1936-42.

13. Søndergaard A, Christensen B, Maindal HT. Diversity and ambivalence in general practitioners' attitudes towards preventive health checks - a qualitative study. BMC Fam Pract 2012;13:53.

14. Rubio-Valera M, Pons-Vigués $M$, Martínez-Andrés $M$, et al. Barriers and facilitators for the implementation of primary prevention and health promotion activities in primary care: a synthesis through metaethnography. PLoS One 2014;9:e89554.

15. Bailie RS, Si D, Connors CM, et al. Variation in quality of preventive care for well adults in Indigenous community health centres in Australia. BMC Health Serv Res 2011;11:139.

16. Lugtenberg M, Burgers JS, Besters CF, et al. Perceived barriers to guideline adherence: a survey among general practitioners. BMC Fam Pract 2011;12:98.

17. Lugtenberg M, Zegers-van Schaick JM, Westert GP, et al. Why don't physicians adhere to guideline recommendations in practice? An analysis of barriers among dutch general practitioners. Implement Sci 2009;4:54.

18. Atlas de La Demographie M. atlas_de_la_demographie_medicale_ 2016.pdf, 2016. https://www.conseil-national.medecin.fr/sites/ default/files/atlas_de_la_demographie_medicale_2016.pdf.

19. Dumont G-F. Régions urbaines, régions rurales. Population \& Avenir 2016;728:3.

20. Portrait démographique de la Suisse, 2009. https://www.bfs.admin. $\mathrm{ch} / \mathrm{bfs} / \mathrm{fr} / \mathrm{home} /$ statistiques/population/effectif-evolution.assetdetail. 346794.html

21. Num-2-2015_population.pdf. http://www.scris.vd.ch/Data_Dir/ ElementsDir/8130/1/F/Num-2-2015 population.pdf

22. Statistique_mdicale_2016_de_la_FMH1.pdf. https://contens $30 . f m h$. $\mathrm{ch} / \mathrm{fmh} /$ ffiles/pdf18/Statistique_mdicale_2016_de_la_FMH1.pdf

23. Sebo P, Maisonneuve H, Cerutti B, et al. Rates, Delays, and Completeness of General Practitioners' Responses to a Postal Versus Web-Based Survey: A Randomized Trial. J Med Internet Res 2017; 19:e83.

24. McGlynn EA, Asch SM, Adams J, et al. The quality of health care delivered to adults in the United States. N Engl J Med 2003;348:2635-45.
25. Asch SM, Kerr EA, Keesey J, et al. Who is at greatest risk for receiving poor-quality health care? N Engl J Med 2006;354:1147-56.

26. McMahon SR, Iwamoto M, Massoudi MS, et al. Comparison of e-mail, fax, and postal surveys of pediatricians. Pediatrics 2003;111:e299-303.

27. Cummings SM, Savitz LA, Konrad TR. Reported response rates to mailed physician questionnaires. Health Serv Res 2001;35:1347-55.

28. Collet TH, Salamin S, Zimmerli L, et al. The quality of primary care in a country with universal health care coverage. J Gen Intern Med $2011 ; 26: 724-30$

29. Virgini V, Meindl-Fridez C, Battegay E, et al. Check-up examination: recommendations in adults. Swiss Med Wkly 2015;145:w14075.

30. Tuppin P, Samson S, Fagot-Campagna A, et al. Dépistage et diagnostic de cancer de la prostate et son traitement en France (2009-2011) selon le Sniiram. Bulletin Epidémiologique Hebdomadaire 2014.

31. Collège de la médecine générale - premiere prescription du PSA chez l'homme asymptomatique. http://www.e-cancer.fr/content/ download/145176/1814733/file/Premiere-prescription-PSA-hommeasymptomatique-v3_2016.pdf

32. Cornuz J, Auer R, Senn N, et al. [Prevention and screening in adults: trends in 2010]. Rev Med Suisse 2010;6:2282-5.

33. Cornuz J, Jacot-Sadowski I, Nanchen D, et al. [Primary prevention and screening in adults: update 2014]. Rev Med Suisse 2014;10:177-85.

34. Murray CJ, Barber RM, Foreman KJ, et al. Global, regional, and national disability-adjusted life years (DALYs) for 306 diseases and injuries and healthy life expectancy (HALE) for 188 countries, 1990-2013: quantifying the epidemiological transition. Lancet 2015;386:2145-91.

35. GBD 2015 DALYs and HALE Collaborators. Global, regional, and national disability-adjusted life-years (DALYs) for 315 diseases and injuries and healthy life expectancy (HALE), 1990-2015: a systematic analysis for the Global Burden of Disease Study 2015. Lancet 2016;388:1603-58.

36. Le Breton-Lerouvillois $\mathrm{G}$. La démographie médicale en région Paysde-la-Loire: situation en 2013. https://www.conseil-national.medecin. $\mathrm{fr} / \mathrm{sites} /$ default/files/pays de la loire 2013 0.pdf (cited 1 Jul 2016).

37. Wirth C, Stanga Z, Birrenbach T, et al. [Evidence based check-up: the general medical point of view]. Praxis 2013;102:647-56.

38. Pasche S, Broers B, Favrod-Coune T. [How to have a clear vision when considering all the different recommendations of moderate alcohol consumption?]. Rev Med Suisse 2012;8:1831-5.

39. Broers B, Favrod-Coune T. Recommandations en matière d'alcool: comment s'y retrouver? Dépendances 2014.

40. HAS. cancer de la prostate1. http://www.oncopaca.org/sites/default/ files/2012_guide_ald_cancer_prostate_inca_has_pro.pdf (cited 6 Aug 2016).

41. Afssaps - prise en charge du patient dyslipidémique. http://www. unilever-pro-nutrition-sante.fr/wp-content/uploads/2014/03/ Afssaps-2005-Prise-en-charge-du-patient-dyslipid\%C3\%A9miquerecommandations.pdf (cited 6 Aug 2016).

42. ANAES - modalités de dépistage et diagnostic biologique des dyslipidémies en prévention primaire. http://www.em-consulte.com/ showarticlefile/124707/pdf_43509.pdf (cited 6 Aug 2016).

43. Société française d'alcoologie - dépistage, diagnostic et traitement. http://www.sfalcoologie.asso.fr/download/RBP2014-SFA-MesusageAA.pdf (cited 6 Aug 2016).

44. INPES - alcool et médecine générale. http://inpes. santepubliquefrance.fr/CFESBases/catalogue/pdf/1146.pdf

45. Principales dyslipidémies : stratégies de prise en charge: Haute Autorité de Santé. https://www.has-sante.fr/portail/jcms/c_2039802/ fr/principales-dyslipidemies-strategies-de-prise-en-charge

46. Fedewa SA, Cullati S, Bouchardy C, et al. Colorectal cancer screening in Switzerland: cross-sectional trends (2007-2012) in Socioeconomic Disparities. PLOS One 2015;10:e0131205

47. Avis d'experts relatif à l'évolution du discours public en matière de consommation d'alcool en France organisé par Santé publique France et l'Institut national du cancer: Santé publique France. http://www.santepubliquefrance.fr/Actualites/Avis-dexperts-relatif-a-I-evolution-du-discours-public-en-matiere-deconsommation-d-alcool-en-France-organise-par-Sante-publiqueFrance-et-I-Inca

48. Cohidon C, Cornuz J, Senn N. Primary care in Switzerland: evolution of physicians' profile and activities in twenty years (1993-2012). BMC Fam Pract 2015;16:107.

49. Deveugele M, Derese A, van den Brink-Muinen A, et al. Consultation length in general practice: cross sectional study in six European countries. BMJ 2002;325:472.

50. Gelly J, Le Bel J, Aubin-Auger I, et al. Profile of French general practitioners providing opportunistic primary preventive care-- 
an observational cross-sectional multicentre study. Fam Pract 2014;31:445-52.

51. Microsoft Word - AGREE II - User's Manual and 23-item Instrument FINAL VERSION 2009 UPDATE 2013.docx - AGREE-II-UsersManual-and-23-item-Instrument_2009_UPDATE_2013.pdf. http:// www.agreetrust.org/wp-content/uploads/2013/10/AGREE-II-UsersManual-and-23-item-Instrument_2009_UPDATE_2013.pdf

52. Reid RJ, Anderson ML, Fishman PA, et al. Relationship between cardiovascular risk and lipid testing in one health care system: a retrospective cohort study. BMC Health Serv Res 2015;15:281.
53. Korenstein D, Falk R, Howell EA, et al. Overuse of health care services in the United States: an understudied problem. Arch Intern Med 2012;172:171-8.

54. Virani SS, Woodard LD, Wang D, et al. Correlates of repeat lipid testing in patients with coronary heart disease. JAMA Intern Med 2013;173:1439-44.

55. Michael Allan G. Should primary care guidelines be written by family physicians?. Can Fam Physician 2016;62:705-6.

56. Fisher RJ. Social Desirability Bias and the Validity of Indirect Questioning. J Consum Res 1993;20:303-15. 